\title{
Performing Transcendence Through Movement, Perception and Technology
}

\author{
Afif Dimitri Haddad \\ ARTLAB, 1804 Rmeil, Gouraud St - Beirut,Lebanon \\ Ad.haddad93@gmail.com
}

\begin{abstract}
This paper is a reflection on how the introduction of technology to performance arts enables a transcendence of the human body through a real-time mediation between a physical and a virtual world.
\end{abstract}

Transcendence. Human Body. Performance Arts. Virtual Reality. Augmented Reality Motion Capture. Dance. Theatre.

\section{FROM SUFI WHIRLING TO THE VIRTUAL DERVISH}

I remember the first time I saw a Dhikr ritual (recitation of devotional Islamic prayers to remember Allah) where Whirling Dervishes were endlessly turning with their beautiful tannoura (skirt) floating in mid-air as if suspended in time; what I was looking at was extremely entertaining. I was six at that time, on holidays in Damascus with the family, and as soon as we went back home, my sister and I readapted this ritual into our own game called "Taztouz". I don't know if it was in reference to Looney Tunes' Tasmanian Devil, or in reference to the childish Arabic slang insinuating the buttocks, but we would turn and turn endlessly, disconnecting from the space around us, seeing everything in lines of colour, until we lose control, fall and watch the space dance for us; even though we did not know it, it was our first encounter with transcendence. In late 2018, 20 years after my first encounter with the whirlers, I saw another ritual in Egypt. This time it was different. I was not entertained or fascinated by their physical capabilities. I was simply dumbfounded by the gaze that the meditators had. They were in trance, disconnected from their bodies, absent from the space we both physically occupy. As a dancer, I understood for the first time that the movement that I see before me is not about its form or progression, it was an active internal reflection in search of spirituality. This time, when I went back home, I started looking into this Sufi practice and its origin. I was surprised to learn that what I thought was an exclusive religious meditation was actually closely linked to science and astrology: the dervishes whirl, like the planets around the sun, in counter-clock motion around their heart with arms open, the left one pointing to the earth and the right one to the sky allowing harmony with the universe itself.

Interested in how science and movement can be joined together to reach transcendence, I started researching modern ways through which science, or technology to be more specific, can lead to transcendence when coupled with movement. With an inexplicable coincidence, I fell on Yacov Sharir and Diane Gromala's Dancing with the Virtual Dervish: Virtual Bodies (1995). It consisted of a virtual reality performance taking place inside a human body constructed by Gromala with X-rays, MRIs and other medical imagery systems, in which Sharir dances in the centre of the thoracic cage, replacing the heart. Viewers experience this performance through a head-mounted display, data gloves and interactive video projections, enabling them to interact with their surroundings. Sharir talks of this new virtual technology that can "manipulate, extend, and distort images of the body" allowing him to experience an embodiment and disembodiment physically and spiritually (Sharir1995). These words were a gateway for me to delve further in the research of the contemporary technological mediated transcendence that I will explore further in this paper.

\section{A BRIEF HISTORY OF MOVEMENT AND SCIENCE}

The body has been central to scientific studies through imagery in the 1800s. The earliest form of motion capture was born with photography researchers who were interested in how movement exists in time and space. By rendering clear images from humans and animals in motion with 
chronophotographs, Muybridge studied habitual human movements while in motion. Etienne-Jules Marey however used the same technique but was more interested in the abstraction of the human body into lines and shapes. These experimentations gave birth to two directions in performance which are clearly visible in Cunningham's work:

(i) Choreographed movement that is created specifically to be captured on camera or "dance-on-film" (Birringer-1999-362) explored in Beach Birds for Camera (1993)

(ii) Pre-recorded visuals that are used as projections onto choreographed movements explored in Biped (1999) developed with The OpenEnded Group

In these creations, the viewer experiences technology which is based on motion capture and somatic practices as two distinct elements. However, with the development of motion capture and the introduction of augmented reality, choreographers and technicians were able to link the body and technology consolidating them to one entity where movements and a computer generated images interact in real time, transforming what used to be "derived performances" to "interactive performances" (Mullis-2013) where subjects perform in an altered reality transcending the physicality of the body or the space.

In the 1900s, non-photographic explorations in the field of movement in relation to space and time led to the creation of notation systems. Rudolf Laban, a dance artist and theorist elaborated the Labanotation based on signs and symbols used to describe movement in relation to the kinesphere. This system highlighting joints and lines of the body was later used as a tool to animate characters on screen giving birth, through gaming, to performance in virtual reality.

Today, being a gamer by hobby and a dancer, I realize how the combination of technology and movement that allowed the duality of performing in the virtual world and performing in an altered reality reminding me the entertaining and then spiritual impression I had when I saw the whirling dervishes. Therefore, I split my study into two tracks in which I investigate transcendence through the amalgamation of movement and technology.

\section{PERFORMING IN THE VIRTUAL WORLD}

In 1992, Sega Genesis released a platform game called Kid Chameleon. the plot was around the main character Casey, who was abducted by the boss Wild Side from the real world into a virtual reality video game. The protagonist had to kill the boss to free the abducted players. Today, Sega's game has become reality. We have reached a time where players access video games with their own bodies and can interact with other players within the virtual realm. It occurred to me once, while hiking down the mountains of the Old Kingdom in Skyrim: Elder Scrolls $V$, I can control the character's body better than I can control my own. I have spent over $150 \mathrm{~h}$ in total on this game riding horses, climbing mountains, fighting enemies, I even got married, when in real life, I haven't done most of them.

In 2011, Microsoft launched the Kinnect motion capture, a ground-breaking gaming tool which is today used in performance. The small rectangular box houses a camera that captures movements and translates it into data. When connected to an Xbox, the Kinnect mirrors the player's motion in an avatar of his/her choice that can be manipulated in games. When I saw the advertisement of the Kinnect, I was in awe to see that the first motion that the cast did was dance in front of the camera, seeing her avatar move as she is, performing her metamorphosis onto a screen. With motion capture and VR systems becoming easily accessible, it's only a matter of time before humans start spending more time as their virtual alter-egos than their real physicality. People would then have transcended the limitations of their bodies to exist in a parallel virtual world where the mobility and some senses are enhanced with the virtual world gaining power over the real one.

A major trend hit social media recently called the Fortnite Challenge. Fortnite, a battle royal game where 100 players are dropped into a map killing each other until there is only one survivor, introduced a celebratory dance repertoire that players use in the game. However, these dances which were programmed into a computer by animators reflected on the way we move when people started doing it in real life overlooking their own physicality and the movement it generates, embodying their avatars. In 2019, the British army released a recruitment campaign targeting gamers specifically titled Your Army Needs You, and Your Stamina(https://www.youtube.com/watch?v=d8NIN NV5gF0). Stamina is a word commonly used in gaming referring to the ability of movement of a player before his breath runs out. By targeting gamers using their own slang, the British army opened a door for gamers to use their virtual abilities in reality. Seeing that, I ask myself: are we, gamers, seeking to unify physical and virtual identity extending our capacities? Is merging the 
two realities a way of becoming more wholesome as human beings?

\section{PERFORMING IN ALTERED REALITY}

Unlike transcending the physicality of the body into a virtual world through the embodiment of an avatar, performing in an altered reality seeks to modify the three-dimensional plane we exist in through the intervention of technology. It does not place the performer in a virtual world, however it tends to redefine the reality we exist in through the communication between movement and technology, the space is either modified into a new one where the $X Y Z$ axis are blurred or through reshaping and reconstructing the performer by the use of lights and sounds.

Technologically mediated performances have come a long way since the innovating creations which Riverbed Studios has created with Merce Cunningham and Bill T. Jones in the 1990s. I will develop below my research topics, divided into four categories representative of elements of transcendence. However, these categories are not mutually exclusive, and performances might exist in two categories at the same time.

\subsection{REDEFINING SPACE}

In Biped (1999), Merce Cunningham offers a completely new experience for the public by placing transparent films in front of the dancers on which he projects visuals and pre-recorded abstract movement. Even though this performance does not use real-time motion capture and fits in Mullis' category of derived performance, I believe it was one of the earliest forms of redefining space in the history of dance that inspired many who came after him. Traditionally, the public experiences a performance in a theatre, the "dance space" (De Spain-2000-6) where movement and scenography unfold, and progress, prescribed inside a horizontal lit parallelepiped (in analogy to the modernist white cube) located in front of the seats. However, with the introduction of motion capture in performance and linking them to projections, choreographers and art directors where able to break the parallelepiped, distort, and redefine it, with an everchanging scenography without human intervention. With the help of motion sensors and overhead projectors, Chunky Move's Mortal Engine (2008)(https://www.youtube.com/watch?v=sbjOMu alLVs) under the direction of Gideon Obarzanek, gives the impression that the performer is not subjected to gravity but is moving, suspended in space. The game of light and darkness, the angle and the perspective of the geometric shapes gives the impression that some parts are choreographed on a slope tilting backwards then front. Another great example of this phenomena is Yacov Sharir's
$3 D$

Embodied

(2013)

(https://www.youtube.com/watch?v=1JhFDq9ZnuU $\underline{\mathrm{t}=84 \mathrm{~s}}$ ) where 4 dancers are immersed in a threedimensional video-mapped cube that is in perpetual alteration, as it is linked to a $5^{\text {th }}$ dancer with biofeedback sensors. The sensors collect biodata (heart rate, breath rate, muscular activity...) in real time and transforms it into an audio-visual field to the audience. The space is thus shaped by the movement of a dancer, creating a "mise en abyme" of the space where the performance unfolds. Finally, another interesting approach to this technology is Mark Foehringer's Dances of the Sacred and Profane (2014) (https://vimeo.com/170714123). Inspired by the music of the impressionist period, the creator uses Dr. David Glowacki's Danceroom Spectroscopy and visuals mapped by Camille Utterback to transform the back of the stage into a live drawn digital painting, using his dancers' bodies' as his brush. The stage thus transforms into an artist atelier and the dancers become pigments with which paintings are created.

By the introduction of motion capture technology and projections in performance, we see that the dancers transcend the physical boundaries of the traditional "dance space" by extending their movements into the "representative space of computing" (De Spain-2000-6). However, what becomes of the performer when the space is altered? How does the performer's body evolve in this reimagined reality?

\subsection{REDEFINING THE HUMAN BODY}

Before the intervention of technology in performance, Oskar Schlemmer aimed at redefining the physicality of his dancers in the Triadisches Ballett (Triadic Ballet) (1921-29) in the Bauhaus. Schlemmer transformed his dancers into geometric shapes with big constraining costumes insinuating the mechanised modern world, moving in space by choreographing what has been a human and reduced to forms. The introduction of motion capture and VR technology made possible the anti-gravitational, multi-layered, extended, redefined body, leaving choreographers and art directors with new desires of the performing body (Birringer-1999-380). Using augmented reality to invite the viewers into a computer space, in MAN A for VR (2015) (https://www.youtube.com/watch?v=45BOhBSF U 4) Gibson and Martelli track their performers' movements in studio and recreate them virtually, reducing them into lines and shapes, camouflaging them into the background installed in a physical space. In order to see the performers, viewers must download a mobile application emulating a camera, and point it towards the large print where they see 
virtual dancers on their devices move. The geometric abstraction of the performers is thus ordered to existence on the viewers command. Digital artists Adrej Boleslavsky and Maria Judova take the abstraction of their dancers even further by reducing them dust. Dust (2016) (https://vimeo.com/210525711) transforms performers whose motion was captured in studio, through volumetric recordings and photogrammetric imagery, and reduce them to micro-particles inviting the public to interact with the performers through an immersive VR headset.

By creating a virtual world in which performances take place, the performer's body has an opportunity to reinvent itself by exceeding the physicality of its flesh, becoming versatile, existing in multiple realities at once. This new technological possibility in performance does not only affect the dancers' bodies, it reshaped the way the audience experiences the performance. Through motion sensors, VR and augmented reality, a boundary between the public and the performer is and must be constantly redefined.

\subsection{REDEFINING PERFORMER-PUBLIC RELATION}

In the process of collaboration between man and machine, performance arts opened a door for the inclusion of the public within their performance whether it's literal, by reaction, or by interaction. Stelarc for instance used technology for a literal access of the performer's body by using a medical endoscopic camera to create a live sculpture. In Stomach Sculpture (1993), the artist ingested the micro-camera not as prosthetic implant but as an aesthetic addition (Stelarc-1993), to produce a communicative choreography, a pas-de-deux, between the beeping and blinking machine and the empty stomach shifting the performance that usually unfolds in a public space to an experience where the viewers see his interior private physiological space. Sandro Massai, on the other hand, seeking to provide a similar experience to the public, invited them to access his body by wiring his vital signs to the space. In My Body Your Room (2014) (https://vimeo.com/131655145), the performer linked, through medical vital signs tracking equipment, his heart rate to the lamps in the space and he transformed his breathe sounds into the original score of the performance. By controlling the sound and lights with the vital signs of the performer, the viewer finds himself in a binary space where the performance happens doubling into the body of the performer himself that now he/she can access. The space and the performer become indivisible.

Other interactions between the public and the performer were made possible using cameras and internet connections or sensors. Thecla Schiporst for instance made her body accessible to people in Bodymaps: Artifacts of Touch (1996) by placing 15 electromagnetic field sensors beneath a white velvet surface upon which is projected images of the artist's body, modified only by the touch of the viewer with computer generated images. Conversely, by using ISDN connection and cameras, Paul Sermon invited the viewers to teleinteract with him in real time during Telematic Dreaming (1992) blurring the lines between telepresence and physical presence. The performance begins as a person walks into a room and is presented with a bed where Sermon is projected on his own bed though videoconference, the viewer and the performer interact in two separate locations. Here, the sense of touch is replaced with vision and distance is dissolved by the presence of two beds in a telematic space creating a new immersive virtual consciousness. As the viewer enters the room, he/she is more aware of the physical space but as the performance happens, the consciousness shifts to the interaction with the performer where subjects act in a real space but are animated in a virtual one. The barrier between the performer and the public is broken, the feeling of intimacy with psychological complexity of the bed is heightened through the telematic experience made possible by the mediation of physical acts, computers and internet connection.

Talking about human interactions through internet connection brings back the subject of gaming and its online platforms where players, human avatar performers interact together in a virtual world. Gilles Jobin and Artanim, inspired by the gaming and avatar visual format, created VR_I (2018), "a dance piece in virtual reality" (Jobin-2018). As a dancer on a theatre stage, I find the inclined architecture occupied by chairs in rows leading to balconies often overwhelming, transforming the public into one big complex of giant human flesh with thousands of eyes directed towards me. In his reality, Jobin inverted the relation between the public and the performer creating a world where five viewers can access and interact under the steps of five giant dancers. The dancers move at times and inspect the tiny avatars of the viewers at others, as if they were the ones performing in the new reality.

Revaluating the traditional "dance space" is an inevitable result of the shift in the relation between the performers and the public. However, at the current stage of technological research, a considerable amount of technical material and wiring is required reducing the number of viewers, users in some cases, who can actively experience network and virtual performances. 


\subsection{REDEFINING BODY LIMITS}

Rethinking and reinventing body limits is ineluctable when the space, the body and the relation between entities is redefined. When asked about the importance of technology in dance, Cunningham replies "it's the possible way you can see something in a way you haven't. It's something you've been dealing with all your life and you can see it in another way... I think technology is absolutely a marvellous way to open your eyes again" (De Spain-2000). Through the introduction of motion capture to dance, the creation role of a choreographers has been supported by, or even shifted to, the technical output of the data collected; in a simplified way, the choreographer or the performer does not create from his personal experience, knowledge and repertoire, the creation process is dictated by an ongoing communication between the subject and the computer processing motion data. If we look at David Rokeby's Very Nervous System (1982-91) for example, by mapping his body to instrument sounds, we notice that his movement is not dictated by personal somatic choices, but by sonic choices.

Interestingly, this technology has been put to a non-scientific use for neuro-rehabilitation. Using a similar technique with an identical output, Robert Wechsler re-elaborated the visual-sonic mapping through motion capture devices to work with people with limited abilities. With MotionComposer, Wechsler uses two highly sensitive motion capture cameras linked to a software that recognizes movements as small as a simple eye blink. Similar tools have been used in more a more scientific process with the Embedded Arts Neuro-recovery Project where movements are linked to virtual brush strokes. As a result, the program undermines the physical movement and range of motion in the eye of the subject and focuses more on the repercussion that the gesture has on the virtual screen.

This extrapolation of movement into shapes coming from within the people with disabilities is further explored by Eric Minh Cuong Castaing in his experimentation in 2016 with L'Age d'Or. The artist combined dancers and children with disabilities to create movement by stimulating human senses with colours, textures and sounds as a starting point. He then introduced VR glasses to the kids linked to cameras worn by dancers offering a visual stimulation to the kids in order to inspire them to cocreate a dance choreography. The experiments and collected material were finally put together into an animation using motion capture of the dancers and kids transforming them into coloured textures and patterns.

The inclusion of technology in dance seems quite intrinsic. However, it might be worth to ask ourselves, how did performance arts come to this? How can inorganic and organic entities coexist so naturally?

\section{THE “DEVICE PARADIGM' AND PERFORMANCE}

"In a device, the relatedness of the world is replaced by machinery, but the machinery is concealed, and the commodities, which are made available by the device, are enjoyed without encumbrance of or the engagement with a context" (Borgmann, 1984, 47).

Modern society is defined by the Borgmann's device paradigm through its acceptance, and constant demand of technology, which made the introduction of the computer to dance inescapable. This phenomenon transitioned what is the "most human of the arts, by simple logic that its medium of expression is the human body itself" (De Spain, 200,11 ), from a movement-based art form to a medium based art form. Eric Mullis discusses this shift is parallel to shift from Phenomenology to Ontology within the performance space (Mullis, 2013, 120). I tend to think the exact opposite: for the viewer, the ontological nature of the performance, based on the experience of a somatic kinesis, has changed into a phenomenological experience, redirecting the focus to an audio-visual virtual experience rather than to the performers/dancers themselves.

Two bidirectionalities arise with immersive performances:

(i) Performer-Space: the performer does not occupy the space unilaterally anymore. The computer processing the collected data entails some requirements. As a result, the performer and the space evolve together in time as the performance happens.

(ii) Performance-Public: through the interactivity that techno-dance implies, the public is no longer separated from the performance, they become an active unit in the performance, sometimes generating their own input in the virtual existence that the performance exists in.

Furthermore, the inclusion of the public is accentuated by decentralizing the creative process from the creator to the computer or program involved. This opens possibility to people who have never danced before to perform through a successful communication with their virtual counterpart.

Now that techno-performance has become accessible to both experienced and non- 
experienced practitioners, where does transcendence fit?

\section{TRANSCENDENCE THROUGH TECHNOLOGY}

Transcending is the act of going beyond a range or limit. In spirituality, it aims at exceeding our physical existence which as we have seen, is mainly explored and developed in the field of technological mediated performances. Moreover, the computer being programmed to be only interested in movement tracking is indifferent to the social constructs that characterize us and does not dissociate between gender, race, ethnicity, age... when projecting its subject into virtuality.

"There's something very healthy about this whole virtual dance thing. It's confronting us with what we really believe about the transcendent properties of our art form, and gives it validity" Bill T. Jones says when talking about his experience with Ghostcatching (De Spain, 200, 15). Could the computer activated human disembodiment be an evolution of the astrologically linked whirling meditation of the Sufis? Is the intervention of the computer in movement our gateway into a first stage of transcendence where everyone is equal devoid of social constructs? One might argue that transcendence is not a performative practice, it comes from within. I would say that with the intensive use of social media, the lines between reality and virtuality have been blurred, reshaping our whole existence into a performance.

\section{REFERENCES}

Birringer, J. (1999). Contemporary Performance/Technology. Theatre

Journal, 51(4), 361-381

Borgmann, A. (1984) Technology and the Character of Contemporary Life. The University of Chicago Press, Chicago.

De Spain, K. (2000) Dance and Technology: A Pas de Deux for Post-Humans. Dance Research Journal, 32/1, Summer 2000, 2-17

Mullis, E. (2013). Dance, Interactive Technology, and the Device Paradigm. Dance Research Journal, 45(3), 111-123

Stelarc (1993) Stomach Sculpture. https://stelarc.org/?catID=20349 (7/21/2019) 